\title{
Relative growth rate and biomass allocation in 20 Aegilops (Poaceae) species
}

\author{
By RAFAEL VILLAR ${ }^{1 *}$, ERIK J. VENEKLAAS ${ }^{1} \uparrow$, PEDRO JORDANO ${ }^{2}$ \\ AND HANS LAMBERS ${ }^{1,3}$ \\ ${ }^{1}$ Department of Plant Ecology and Evolutionary Biology, Utrecht University, P.O. Box \\ 800.84, 3508 TB Utrecht, The Netherlands. \\ ${ }^{2}$ Estación Biológica de Doñana, Consejo Superior de Investigaciones Cientificas, Avda de \\ María Luisa s/n, Pabellón del Perú, E-41013 Sevilla, Spain \\ ${ }^{3}$ Plant Sciences, Faculty of Agriculture, The University of Western Australia, Nedlands \\ WA 6009, Australia
}

(Received 17 December 1997 ; accepted 14 August 1998)

\section{S U M M A R Y}

This paper analyses relationships between relative growth rate (RGR), seed mass, biomass allocation, photosynthetic rate and other plant traits as well as habitat factors (rainfall and altitude) in 20 wild species of Aegilops L. and one closely related species of Amblyopyrum (Jaub. \& Spach) Eig., which differ in ploidy level (diploid, tetraploid and hexaploid). The plants were grown hydroponically for $20 \mathrm{~d}$ in a growth chamber. The relationships between parameters were calculated either using the phylogenetic information (phylogenetically independent contrasts, PIC) or without using the phylogenetic information (trait values of taxa, TIP). The results using the two approaches were very similar, but there were a few exceptions in which the results were different (e.g. RGR vs. seed mass). Specific leaf area (SLA) was positively correlated with leaf area ratio (LAR) and negatively correlated with net assimilation rate (NAR), which together resulted in the absence of a correlation between SLA and RGR. Leaf photosynthetic rates (expressed on a mass or area basis) showed no correlation with RGR. RGR was positively correlated with the stem mass ratio and negatively with root mass ratio. Species with a lower $\mathrm{d}$. wt percentage have a higher RGR. Aegilops species from locations with higher annual rainfall invested less biomass in roots and more in shoots (leaves and stems) and had a higher RGR. Diploid species had a lower seed mass and initial mass than the hybrids (tetraploid and hexaploid species), but there was no correlation of RGR with ploidy level. Polyploid species, which have higher seed mass, occur at a higher altitude than diploid species. Our results show that variation in RGR in Aegilops and Amblyopyrum spp. is associated mainly with variation in biomass allocation (proportion of biomass in stems and roots) and d. wt percentage, and not with variation in SLA, leaf photosynthetic rates or seed mass.

Key words: Aegilops L., biomass allocation, photosynthesis, phylogeny, rainfall, relative growth rate, seed mass, wild wheat.

\section{INTRODUCTION}

The potential RGR of plants (the rate of increase in biomass per unit biomass) and its relationship with different plant traits has been studied extensively in recent years (Lambers \& Poorter, 1992; also see Poorter \& Van der Werf, 1998 for a review). The aims of these studies have been to identify causes of variation in RGR between species and the ecological

\footnotetext{
* To whom correspondence should be addressed at (present address): Departamento de Biología Vegetal y Ecología, Facultad de Ciencias, Universidad de Córdoba, Avda San Alberto Magno s/n, 14004 Córdoba, Spain.

E-mail: bv1vimor@uco.es

$\uparrow$ Present address: CIAT, Centro Internacional de Agricultura Tropical, Apartado Aéreo 6713, Cali, Colombia.
}

consequences of differences in RGR. Variation in RGR can be associated with variation in LAR (total leaf area:total d.wt) or NAR (rate of increase in plant mass per unit leaf area) (West, Briggs \& Kidd, 1920). LAR is a morphological parameter that is the product of the leaf mass ratio (LMR, leaf d. wt:plant d. wt) and the specific leaf area (SLA, leaf area:leaf d.wt). Conversely, NAR is a complex parameter including physiological characteristics such as the photosynthetic rate of leaves and respiration rate of different organs (Lambers et al., 1989). Recently, Poorter \& Van der Werf (1998) concluded from an analysis of literature data that LAR is the most important factor in explaining inherent variation in RGR in herbaceous species, and that differences in 
LAR were mainly due to variation in SLA. However, some experiments might yield results that deviate from this general trend (see Appendix 2 in Poorter \& Van der Werf, 1998).

The importance of a high RGR for a plant could be a high plant mass after a certain period of growth, but this mass also depends on the initial mass, which in turn is related to seed mass (Van Andel \& Biere, 1989; Fernández Alés, Laffarga \& Ortega, 1993; Marañón \& Grubb, 1993). Both RGR and seed mass, therefore, determine the size of a seedling at any time after germination. The two parameters might not be independent since seed mass is often negatively correlated with RGR (Fenner, 1983; Gross, 1984; Marañón \& Grubb, 1993; Shipley, 1995; Cornelissen, Castro Diez \& Hunt, 1996). The reason for this negative correlation remains unclear. However, in some studies such a correlation is absent (Choe et al., 1988; Shipley \& Peters, 1990 b) or positive (i.e. seed mass positively correlated with RGR, Meerts \& Garnier, 1996). In general, most studies on the relationships between RGR and other parameters have used individual species as independent data points, despite the fact that related species with a common history can have similar traits, in which each point (species) is not independent of others. One statistical assumption for regression and correlation is the independence of the points. Several techniques have been used to solve this problem; a frequently used one is to calculate phylogenetically independent contrasts (PIC) (see Silvertown, Franco \& Harper, 1997, and references therein). Only two recent studies (Saverimuttu \& Westoby, 1996; Swanborough \& Westoby, 1996) have analysed the differences in RGR and the relationship with seed mass using pairs of phylogenetically independent species. Using this approach we tried to determine whether changes in two parameters (e.g. RGR vs. seed mass) have evolved in the same direction for all species (e.g. an increase in seed mass coincided with a decrease in RGR during the evolution of the species).

Whereas general trends between RGR and other parameters might appear when species from divergent taxonomic groups are compared (Poorter $\&$ Remkes, 1990), this pattern can change when the taxonomic range of the species studied is restricted. Garnier (1991) showed that if one restricts the taxonomic scope (i.e. studying the relationships between variables within one order: monocotyledons or dicotyledons in Marañón, 1988; Poorter \& Remkes, 1990), the correlation between RGR and biomass allocation vanishes. Conversely, if taxonomic variation is not restricted (i.e. studying species of monocotyledons and dicotyledons together), there is a correlation between these variables (Marañón, 1988; Poorter \& Remkes, 1990). So, the relationship between RGR and other variables could be different in a sample of taxonomically related species when compared with those in a sample of unrelated taxa.
Until now, most of the studies on RGR have used species that belong to different genera and families and only a few have been restricted to one taxon (e.g., within one family or genus; Garnier, 1992; Van Arendonk \& Poorter, 1994; Atkin, Botman \& Lambers, 1996). Moreover, detailed hypotheses about the covariation between traits across species are best assessed within particular groups of species (e.g. congeners), rather than at higher taxonomic levels (Donoghue \& Ackerly, 1997).

For these reasons, we investigated the RGR and growth-related parameters in 20 wild species from the genus Aegilops L. (Poaceae) and one wild species of a closely related genus (Amblyopyrum). Until recently Amblyopyrum muticum was considered to belong to the Aegilops genus (Van Slageren, 1994).

The Aegilops genus comprises 22 annual species which are distributed in the Mediterranean region and Western and Central Asia (Van Slageren, 1994). The species vary in level of ploidy (diploid, tetraploid and hexaploid) and are found in habitats with different annual rainfall $\left(75-1400 \mathrm{~mm} \mathrm{yr}^{-1}\right)$ and altitude (minus $400 \mathrm{~m}$, Dead Sea area, up to $2700 \mathrm{~m}$ ) (Van Slageren, 1994). The Aegilops genus is of agronomic interest as some species have contributed to the genome of modern wheat species (Triticum). Aegilops species might be a source of valuable traits for future wheat cultivars (Lambers et al., 1995), such as higher grain quality, higher disease resistance and heat and cold tolerance (Feldman, 1991) or higher photosynthetic rates (García et al., 1997). By screening physiological, morphological and anatomical parameters related to productivity and the efficiency of water and nutrient use in the Aegilops genus, potentially useful traits might be identified for incorporation into future wheat cultivars.

The objectives of this study are: (1) to understand the association between plant traits such as LAR, SLA, NAR, photosynthetic rate and biomass allocation with interspecific variation in RGR in a large number of Aegilops species; (2) to analyse the importance of seed mass and ploidy level for plant growth rate and other traits; (3) to relate plant traits with habitat factors; and (4) to generate hypotheses about the evolution of these plant traits within the Aegilops genus.

\section{MATERIALS AND METHODS}

\section{General procedures}

We grew 20 species of Aegilops and one species of Amblyopyrum hydroponically for $20 \mathrm{~d}$. The species differed in their ploidy level (diploid, tetraploid and hexaploid) (Appendix 1). The seeds, obtained from ICARDA (International Center for Agricultural Research in the Dry Areas, Aleppo, Syria), had been collected at different locations in the Mediterranean area, Middle East and Central Asia (Appendix 1). 
Nomenclature and ploidy level follow Van Slageren (1994) and Waines \& Barnhart (1992), respectively. Data on altitude and annual rainfall of the place of origin of the seeds were provided by ICARDA. Aegilops species show seed heteromorphism with large differences in seed weight (up to sevenfold), germination percentage and germination time (Marañón, 1987, 1989). Within each species, large seeds have a high germination percentage, germinating in a few days and producing seedlings with high initial mass compared with small seeds. These differences make it difficult to combine different types of seeds in studies of RGR, because it is necessary to have a large number of plants of similar size and age. We only used seeds of the largest size class in each species for our experiment, because they are the seeds that germinate after the first rains in autumn and contribute most to the recruitment of the population for the next season (Marañón, 1987). The average seed mass was calculated from two batches of 10 seeds each. Before germination, seeds were stratified at $2{ }^{\circ} \mathrm{C}$ for $1 \mathrm{wk}$. Germination occurred in Petri dishes in a growth cabinet (day-14 h, $20{ }^{\circ} \mathrm{C}, 30 \mu \mathrm{mol} \mathrm{m}{ }^{-2} \mathrm{~s}^{-1}$ PAR; night $-10 \mathrm{~h}, 15^{\circ} \mathrm{C}$ ). After germination, the seedlings were planted in sand and placed in a growth room for $3 \mathrm{~d}$ in the following conditions: day $-14 \mathrm{~h}, 20^{\circ} \mathrm{C}, 500 \mu \mathrm{mol}$ $\mathrm{m}^{-2} \mathrm{~s}^{-1} \mathrm{PAR}, 70 \%$ r.h.; night $-10 \mathrm{~h}, 10^{\circ} \mathrm{C}, 70 \%$ r.h. Light was provided by HPI/T $400 \mathrm{~W}$ E40 lamps (Philips, Eindhoven, The Netherlands). Four seedlings of each species were selected, choosing those with similar size and with the second leaf emerging. The seedlings were transferred to 331 containers with a modified Hoagland nutrient solution (Poorter $\&$ Remkes, 1990). This day was considered day 0 and the plants were then grown for a further $20 \mathrm{~d}$. A maximum of 24 plants were initially grown in each container. The number of plants in each container was progressively reduced to eight, depending on the plant size, to avoid mutual shading. The $\mathrm{pH}$ of the nutrient solution was adjusted daily to $5 \cdot 5$, using $\mathrm{H}_{2} \mathrm{SO}_{4}$. To prevent nutrient depletion, the solution was renewed once a week. Containers were rotated daily within the growth room to minimize effects of environmental variation in the growth room. All plants remained vegetative and none showed dead leaves during the experiment. The plants of the 21 species studied were grown in the same growth chamber at the same time.

Every $5 \mathrm{~d}$, the $\mathrm{f}$. wt of each plant was measured (after blotting the roots gently with tissue paper), after which each plant was returned to the nutrient solution. At day 20, the photosynthetic rate of the youngest fully expanded leaf of each plant was measured with a portable infrared gas analyser (ADC-LCA 2, The Analytical Development Company Ltd, Hoddesdon, UK). Photosynthetic rates were measured $4 \mathrm{~h}$ after illumination, at an irradiance of $500 \mu \mathrm{mol} \mathrm{m}^{-2} \mathrm{~s}^{-1}$ (leaf level), $55 \%$ r.h. and $\mathrm{CO}_{2}$ concentration of $355 \mu \mathrm{mol} \mathrm{mol}^{-1}$ (mean values for all the measurements). After the gas exchange measurements, the plants were separated into leaves, stems (including leaf sheaths) and roots. The f. wt of each fraction as well as the leaf area were determined. Leaf area was measured using an LI-3100 area meter (LI-COR Inc, Lincoln, NE, USA). Dry mass was determined from oven-dried material, after $48 \mathrm{~h}$ at $75{ }^{\circ} \mathrm{C}$.

Initial f. wt and final d. wt are defined as the f. wt at day 0 and the $\mathrm{d}$. wt at day 20 , respectively. The d. wt percentage was calculated as: $(d$. wt $/ f$. wt $) \times$ 100.

All species exhibited exponential growth. In the analysis of data the RGR from the last period of growth was used (from 15 to $20 \mathrm{~d}$ ). There were two reasons for choosing this value of RGR. First, other parameters such as biomass allocation, SLA, photosynthetic rate and $d$. wt percentage were measured in the last period of growth (day 20). Second, the relationship of RGR (last period of growth) with other plant characteristics did not vary substantially when other estimates of RGR (for different periods) were used in the analysis. RGR was calculated as the difference between $\log _{e}$ f. wt at two separate timepoints divided by the difference in time (Hunt, 1982).

\section{Statistical and phylogenetic analysis of data}

Relationships between growth and other variables across the 21 species were analysed by correlation and linear regression using Statistica (StatSoft, 1996) on the trait values of taxa (TIP, i.e. without taking into account the phylogeny). The analysis of the data taking into account the phylogenetic information of these species was made using PIC as implemented in the CAIC package (Purvis \& Rambaut, 1995), which gives independent standardized linear contrasts. To check if two variables were correlated, a regression (through the origin) between the contrasts of the independent variable and the dependent variable was performed. The slope was tested to differ significantly from zero; it gives the relationship between both variables when phylogenetic effects are accounted for. Additionally, a sign test on the PICs was made to assess the statistical significance of the trend of covariation between each pair of variables. The sign test is also robust to deviations of the assumptions underlying the contrasts regressions (Garland, Harvey \& Ives, 1992). The phylogenetic tree of these species (Fig. 1) is based on variation in the restriction patterns of repeated nucleotide sequences (Dvorak \& Zhang, 1990), type of genome (Kimber \& Feldman, 1987; Waines \& Barnhart, 1992) and taxonomy (Van Slageren, 1994). These three independent approaches indicated the same phylogenetic relationships between the 21 species. The tetraploid and hexaploid species, which origin- 


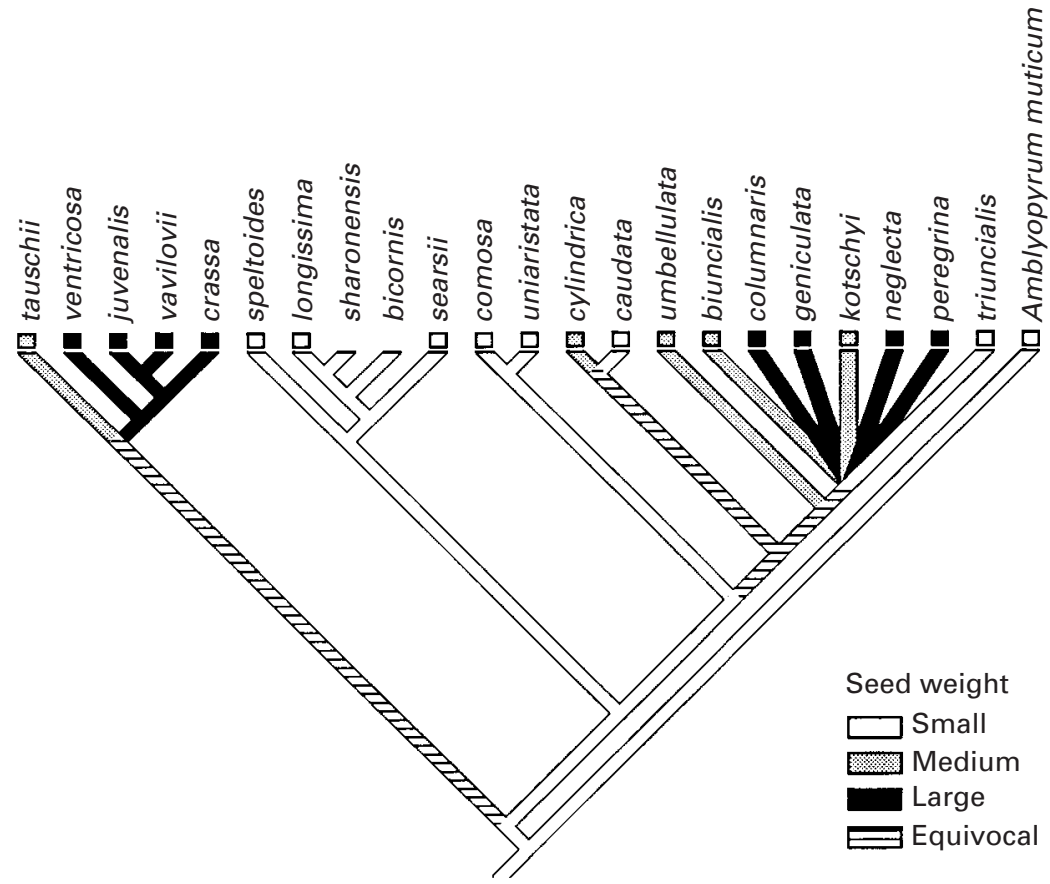

Figure 1. Phylogenetic tree of the Aegilops and Amblyopyrum spp. based on variation in the restriction patterns of repeated nucleotide sequences (Dvorak \& Zhang, 1990), type of genome (Kimber \& Feldman, 1987; Waines \& Barnhart, 1992) and taxonomic affinities (Van Slageren, 1994). Variation in seed mass between species and clades is traced on the tree. Species were classified in three categories according to seed size: large, $>15 \mathrm{mg}$; medium, 10-15 mg; and small, $<10 \mathrm{mg}$. Squares at the tips of the branches indicate taxa with data available for the character traced and the state of the character (fill pattern). No data are available for Ae. sharonensis and Ae. bicornis.

ated from hybridization of diploid and/or tetraploid species, were located at the phylogenetic tree according to the taxonomy of the group (Van Slageren, 1994).

We also compared the traits of the progenitor species with the traits of the species originated by hybridization (tetraploids and hexaploids) using a sign test. A significant sign test was interpreted as evidence for a trend of covariation between ploidy level and the variable being examined. The information on the origin of the hybrids was taken from Kimber \& Feldman (1987), Waines \& Barnhart (1992) and Van Slageren (1994).

Most of the relationships between variables taking into account the phylogeny were consistent with the relationships without using the phylogenetic information (see Table 1). In the results (Table 1), we present the statistics of the analysis ( $r$ and level of significance) using both techniques: without taking into account the phylogenetic information (TIP); and using the phylogeny (PIC). The cases where the results using the two approaches were markedly different are stated in the text.

Comparison of RGR data obtained by non-destructive and destructive growth analysis

To test the reliability of the non-destructive growth analysis to estimate RGR, we carried out an experiment in which the RGR obtained by the nondestructive method was compared with that from a destructive growth analysis. For this purpose, we grew independently six Aegilops spp. with different RGRs (Ae. columnaris, Ae. juvenalis, Ae. umbellulata, Ae. vavilovii, Ae. ventricosa and Ae. tauschii) hydroponically under the same conditions already mentioned, with the exception that both day and night temperature were set at $20^{\circ} \mathrm{C}$.

For the destructive growth analyses, harvests were made on days $0,5,10,15$ and 20 . At each harvest, eight plants were selected at random and the f. wt and d. wt of each fraction (leaf, stem and root) and leaf area were determined. For the non-destructive analysis, we followed the same procedure as described in the previous section.

The effect of the non-destructive method (blotting the root every $5 \mathrm{~d}$ ) on SLA, plant $\mathrm{d}$. wt percentage and root mass ratio (RMR) was also determined.

RESULTS

Comparison of RGR and other parameters obtained by non-destructive and destructive growth analysis

There are two major potential artefacts that the nondestructive analysis could have on RGR. First, the plants might be affected by touching the leaves and/or blotting the roots every $5 \mathrm{~d}$ and this could cause a decrease in RGR (Kraus, Lambers \& Kollöffel, 1993). The comparison of the destructive and nondestructive analyses of six Aegilops spp. showed that RGR (calculated on a f. wt basis for both methods) 


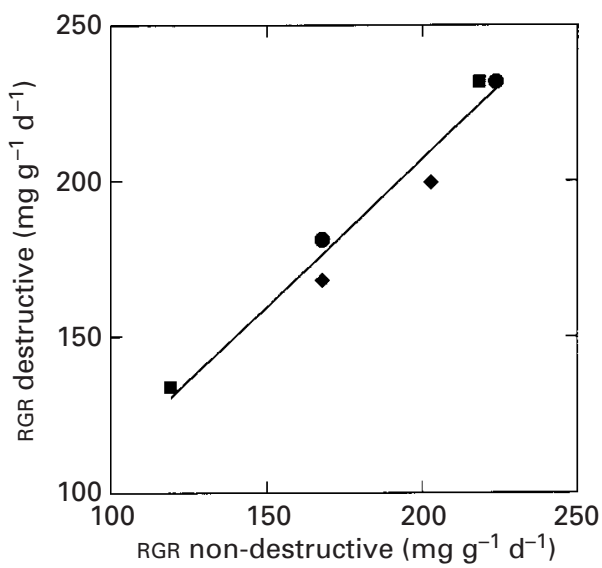

Figure 2. Relationship between relative growth rate (RGR) as determined by destructive growth analysis and RGR as determined by non-destructive analysis for six species of the Aegilops genus (Ae. columnaris, Ae. juvenalis, Ae. umbellulata, Ae. vavilovii, Ae ventricosa and Ae tauschii). Symbols: diploids (O), tetraploids ( $\square$ ) and hexaploids $(\diamond)$. The line represents the linear regression: $y=$ $17 \cdot 46 \pm 0 \cdot 95 x(r=0 \cdot 98, P<0 \cdot 01)$.

decreased by at most $5-11 \%$ using the nondestructive method, and that this reduction was not correlated with RGR.

Second, f. wt-based RGRs are affected by the plant d. wt percentage. If the plant $d$. wt percentage changes between two consecutive harvests, the RGR estimated by $\mathrm{f}$. wt will differ from that using $\mathrm{d}$. wt as a basis. Our results show that, after day 5 of the growing period, the plant d.wt percentage was stable. Therefore, RGR calculated by f. wt measurements was similar (i.e. at most $5 \%$ higher than RGR calculated by d. wt measurements).

Figure 2 shows that RGR obtained by the destructive method (d. wt basis) was strongly correlated $\left(r^{2}=0.96\right)$ with RGR obtained by the nondestructive method (f. wt basis). The slope of the regression line was 0.95 . Therefore, the nondestructive growth analysis provides a very good estimate (at most $5 \%$ lower) of RGR and hence is a convenient and acceptable method for screening a large number of Aegilops species.

Touching and/or blotting of the plant had a minor effect on plants. On average in the non-destructive analysis, plant $\mathrm{d}$. wt percentage was $3 \%$ higher and SLA and RMR were lower by 9 and $1 \%$, respectively, than in the destructive analysis.

\section{What explains the differences in RGR?}

The RGR of seedlings of the 21 species varied between $117 \mathrm{mg} \mathrm{g}^{-1} \mathrm{~d}^{-1}$ for Ae. columnaris and $187 \mathrm{mg} \mathrm{g}^{-1} \mathrm{~d}^{-1}$ for Ae. tauschii (Appendix 1).

Plants with a high RGR tended to have a high LAR or a high NAR $(0 \cdot 05<P<0 \cdot 10$; Table 1$)$, but NAR and LAR were negatively correlated $(P<0 \cdot 001$; Table $1)$, so there were no species having high values for both parameters. Variation in LAR was mainly determined by variation in SLA $(P<0 \cdot 001$; Table 1$)$, and to a lesser extent by that in LMR $(0 \cdot 05<P<$ $0 \cdot 10$; Table 1$)$. The main statistical explanation for the negative correlation between LAR and NAR was the negative correlation between NAR and SLA $(P<0 \cdot 01$; Table 1$)$.

SLA was not directly correlated with RGR $(P>0 \cdot 10$; Fig. $3 a$ ), which is due to the contrasting correlations of SLA with LAR (positively correlated) and with NAR (negatively correlated) (RGR being the product of LAR and NAR).

There was a wide range in photosynthetic rate per unit leaf area in the 21 species, varying from 15 to $21 \mu \mathrm{mol} \mathrm{CO}_{2} \mathrm{~m}^{-2} \mathrm{~s}^{-1}$ for Ae. longissima and Ae. umbellulata, respectively. However, no correlations were found between RGR and photosynthetic rate expressed both on a leaf area $(P>0.40$; Table 1$)$ or leaf d. wt basis $(P>0.60$; data not shown). Photosynthetic rate was positively correlated with NAR $(P<0.05$; Table 1$)$, but negatively correlated with LAR $(P<0 \cdot 01)$. Species with higher photosynthetic rates on an area or mass basis have a low LAR due to a lower allocation to leaves and a low SLA (Table 1). Also species with a high photosynthetic rate showed a higher allocation to roots and had a lower leaf blade area $(P<0 \cdot 05$; Table 1$)$.

Fast-growing species showed a higher allocation to stems $(P<0 \cdot 001$; Fig. $3 b)$ and lower allocation to roots $(P<0.05$; Table 1$)$, but there was no correlation of RGR with LMR. Fast-growing species also showed a higher leaf blade area $(P<0 \cdot 05$; Table 1$)$.

The RGR was negatively correlated with plant $d . w t$ percentage $(P<0 \cdot 05$; Fig. $3 c)$.

\section{Seed mass and ploidy level}

There was a large range in seed mass, from 5.9 to $18.8 \mathrm{mg}$, for Ae. searsii and Ae.juvenalis, respectively (Appendix 1). Relationships of seed mass with other plant variables depended on whether or not the analysis took into account the phylogeny. RGR was negatively correlated with both seed mass and initial f. wt $(P<0.05$; Table 1 , Fig. $3 d)$, although RGR did not show a significant relationship with seed mass when using PIC. The reason for this is apparent when considering the main radiation of Aegilops in two subclades (Fig. 1) that differ in seed mass, so that RGR varies independently of seed mass variation within each subclade.

A large seed mass determined a large initial mass $(P<0 \cdot 001$; Table 1$)$, thus potentially influencing the ability to reach a high final mass (plant biomass after $20 \mathrm{~d}$ of growth). When we analysed the correlates of variation in final mass, we found divergent results from the TIP and PIC analyses. Without taking into account the phylogeny, final mass was significantly related to initial mass $(P<$ $0 \cdot 05$; Table 1$)$, but the correlation vanished when using independent contrasts $(P>0.20$; Table 1). 
Table 1. Summary of regression results for different variables in the 20 Aegilops spp. and one Amblyopyrum sp. studied

\begin{tabular}{|c|c|c|c|c|c|}
\hline \multirow{2}{*}{$\begin{array}{l}\text { Dependent/ } \\
\text { independent } \\
\text { variable }\end{array}$} & \multicolumn{2}{|c|}{ Trait values } & \multicolumn{3}{|c|}{ Independent contrasts } \\
\hline & $r$ & $P$ & $r$ & $P$ & $\operatorname{Binomial}(+/-; P)$ \\
\hline \multicolumn{6}{|l|}{ RGR } \\
\hline Seed M & $-0 \cdot 50$ & * & $-0 \cdot 32$ & n.s. & 4/7; n.s. \\
\hline Initial M & -0.53 & * & -0.59 & $*$ & $2 / 9 ; * * *$ \\
\hline SMR & $+0 \cdot 68$ & **** & $+0 \cdot 72$ & **⿻丷木 & $8 / 3 ;$ n.s. \\
\hline LMR & $+0 \cdot 07$ & n.s. & $+0 \cdot 41$ & n.s. & $7 / 4 ;$ n.s. \\
\hline RMR & $-0 \cdot 52$ & * & $-0 \cdot 63$ & * & $4 / 7 ;$ n.s. \\
\hline Leaf A & $+0 \cdot 49$ & * & $+0 \cdot 73$ & **⿻丷木 & $9 / 2 ; * *$ \\
\hline SLA & $+0 \cdot 19$ & n.s. & $+0 \cdot 37$ & n.s. & $6 / 5 ;$ n.s. \\
\hline$A_{\mathrm{a}}$ & $-0 \cdot 19$ & n.s. & $-0 \cdot 19$ & n.s. & $5 / 6 ;$ n.s. \\
\hline $\mathrm{DM}$ & $-0 \cdot 50$ & $*$ & $-0 \cdot 73$ & 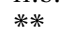 & $1 / 10 ; * * *$ \\
\hline LAR & $+0 \cdot 38$ & $\sim$ & $+0 \cdot 39$ & n.s. & $7 / 4 ;$ n.s. \\
\hline NAR & $+0 \cdot 40$ & $\sim$ & +0.54 & $\sim$ & $9 / 2 ; * *$ \\
\hline \multicolumn{6}{|l|}{ LAR } \\
\hline SLA & $+0 \cdot 91$ & **** & $+0 \cdot 89$ & **** & $8 / 3 ;$ n.s. \\
\hline LMR & $+0 \cdot 37$ & $\sim$ & $+0 \cdot 65$ & * & $11 / 0 ; * * *$ \\
\hline NAR & $-0 \cdot 68$ & **** & $-0 \cdot 66$ & * & $4 / 7$; n.s. \\
\hline \multicolumn{6}{|l|}{ NAR } \\
\hline$A_{\mathrm{a}}$ & $+0 \cdot 44$ & * & $+0 \cdot 49$ & $\sim$ & 7/4; n.s. \\
\hline $\mathrm{RMR}$ & $+0 \cdot 05$ & n.s. & $+0 \cdot 06$ & n.s. & $6 / 5 ;$ n.s. \\
\hline SLA & -0.66 & *** & -0.57 & * & $4 / 7 ;$ n.s. \\
\hline DM & $-0 \cdot 33$ & n.s. & $-0 \cdot 43$ & n.s. & 3/8; n.s. \\
\hline \multicolumn{6}{|l|}{ Final M } \\
\hline Initial M & +0.54 & $*$ & $+0 \cdot 36$ & n.s. & 7/4; n.s. \\
\hline RGR & $+0 \cdot 36$ & $\sim$ & $+0 \cdot 67$ & * & $8 / 3$; n.s. \\
\hline \multicolumn{6}{|l|}{$A_{\mathrm{a}}$} \\
\hline RMR & $+0 \cdot 54$ & * & +0.79 & $* *$ & $10 / 1 ; * * *$ \\
\hline Leaf A & $-0 \cdot 45$ & * & $-0 \cdot 73$ & * & 3/8; n.s. \\
\hline SLA & $-0 \cdot 47$ & * & -0.53 & $\sim$ & $3 / 8 ;$ n.s. \\
\hline \multicolumn{6}{|l|}{ RMR† } \\
\hline Trans & $+0 \cdot 65$ & **⿻丷木 & $+0 \cdot 90$ & **** & $10 / 1 ; * * *$ \\
\hline $\mathrm{A} / \mathrm{E}$ & -0.58 & *** & $-0 \cdot 73$ & **⿻丷木 & $2 / 9 ; * *$ \\
\hline \multicolumn{6}{|l|}{ Seed M† } \\
\hline Initial M & $+0 \cdot 78$ & **** & $+0 \cdot 70$ & **⿻丷木 & $9 / 2 ; *$ \\
\hline SLA & $-0 \cdot 01$ & n.s. & $+0 \cdot 25$ & n.s. & $8 / 3$; n.s. \\
\hline Leaf A & $+0 \cdot 34$ & n.s. & $+0 \cdot 37$ & n.s. & $9 / 2 ; *$ \\
\hline RMR & $-0 \cdot 11$ & n.s. & $-0 \cdot 18$ & n.s. & $3 / 8 ;$ n.s. \\
\hline$A_{\mathrm{m}}$ & $-0 \cdot 41$ & $\sim$ & $-0 \cdot 35$ & n.s. & $2 / 9 ; *$ \\
\hline \multicolumn{6}{|l|}{ Ploidy level $\uparrow$} \\
\hline RGR & $-0 \cdot 27$ & n.s. & $-0 \cdot 26$ & n.s. & 4/7; n.s. \\
\hline Seed M & $+0 \cdot 80$ & **** & $+0 \cdot 64$ & * & 7/4; n.s. \\
\hline Initial M & +0.76 & **** & +0.67 & * & $8 / 3 ;$ n.s. \\
\hline$A_{\mathrm{a}}$ & $+0 \cdot 02$ & n.s. & $+0 \cdot 08$ & n.s. & $6 / 5 ;$ n.s. \\
\hline \multicolumn{6}{|l|}{ Rainfall $\uparrow$} \\
\hline RGR & $+0 \cdot 45$ & n.s. & $+0 \cdot 82$ & * & 4/1; n.s. \\
\hline Seed M & $-0 \cdot 02$ & n.s. & $+0 \cdot 10$ & n.s. & $3 / 2 ;$ n.s. \\
\hline RMR & $-0 \cdot 82$ & *** & -0.94 & *** & $0 / 5 ; * *$ \\
\hline LMR & $+0 \cdot 74$ & ** & $+0 \cdot 78$ & $\sim$ & $5 / 0 ; * *$ \\
\hline SMR & $+0 \cdot 62$ & $*$ & $+0 \cdot 84$ & * & 4/1; n.s. \\
\hline \multicolumn{6}{|l|}{ Seed M } \\
\hline Altitude & $-0 \cdot 46$ & * & $+0 \cdot 33$ & n.s. & 6/5; n.s. \\
\hline
\end{tabular}

Trait values show $r$ values and associated significance for regressions across species based on original values (TIP values); independent contrasts show $r$ values and the significance for the regressions through the origin based on phylogenetically independent contrast values (PIC values). Results of sign tests for the PIC analyses are reported as the number of instances showing a positive $(+)$ or negative $(-)$ trend between the contrast values of the variables being compared, and the associated significance $(P$ value for the binomial expectation of an equal number of positive and negative trends). Significance: $\sim 0.10>P>0.05 ; * P<0.05 ; * * P<0.01 ; * * * P<0 \cdot 001$; n.s., not significant. Abbreviations for variables: Seed M (air-dry seed mass); Initial M (initial f. wt at day 0); SMR (stem mass ratio); LMR (leaf mass ratio); RMR (root mass ratio); SLA (specific leaf area); Leaf A (leaf blade area); $A_{\text {a }}$ (photosynthetic rate per unit leaf area); $A_{\mathrm{m}}$ (photosynthetic rate per unit leaf mass); DM (plant d. wt percentage); LAR (leaf area ratio); NAR (net assimilation rate); Final M (d. wt at day 20); Trans (transpiration rate per unit leaf area); A/E (water-use efficiency, photosynthetic rate/transpiration rate). $\dagger$ Independent variable. 

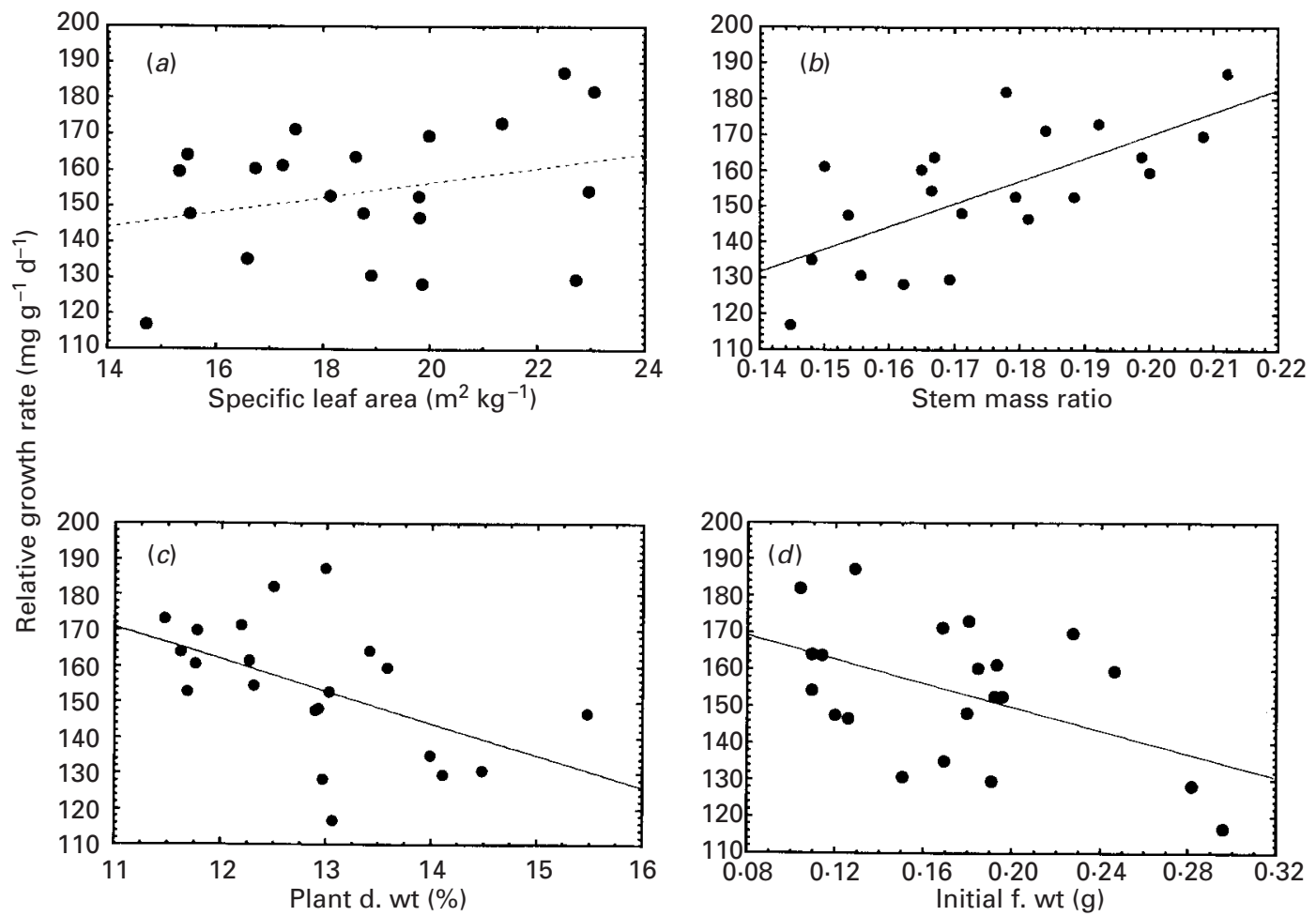

Figure 3. Relationship, for the 20 Aegilops spp. and one Amblyopyrum sp., between RGR and (a) specific leaf area (leaf area/leaf d. wt) $(P>0.10) ;(b)$ stem mass ratio (d. wt stem/d. wt plant) $(r=0.68, P<0.001) ;(c)$ plant d. wt percentage $(r=-0.50, P<0 \cdot 05)$; and $(d)$ initial fresh seedling mass $(r=-0.53, P<0 \cdot 05)$. The lines represent the linear regressions.
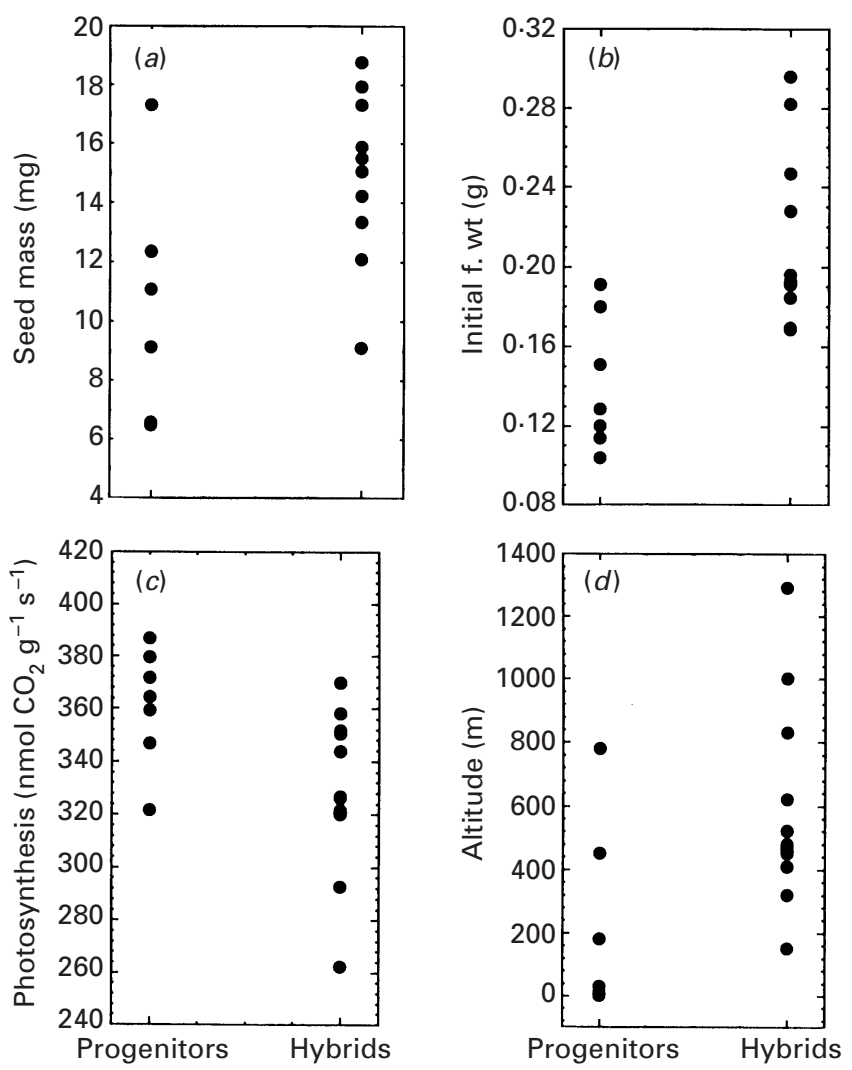

Figure 4. Differences in characteristics between progenitor and hybrid (tetraploid and hexaploid) species: $(a)$ seed mass; $(b)$ initial f. wt; $(c)$ photosynthetic rate per unit leaf mass; and $(d)$ altitude at which seeds were collected. Progenitors are all the diploid species except Ae. longissima, Ae. searsii and Am. muticum, and the tetraploid Ae. crassa. See the genome type in Appendix 1 for the origin of the hybrids. 


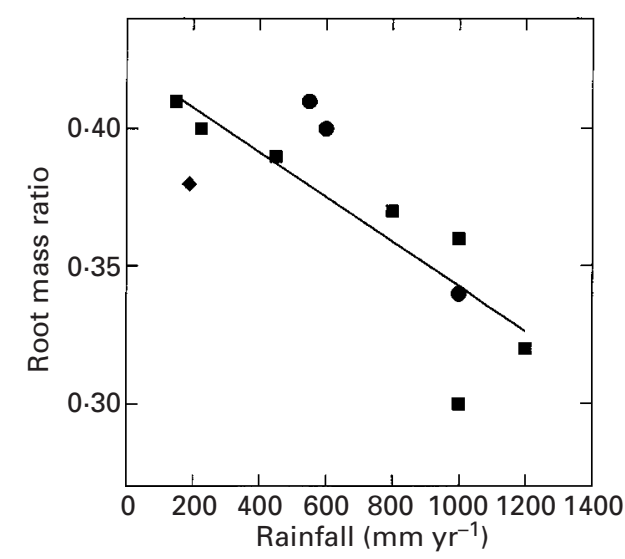

Figure 5. Relationship between root mass ratio and annual rainfall for 11 species of Aegilops. Symbols: diploids (O), tetraploids $(\boldsymbol{\square})$ and hexaploids $(\bullet)$. The line represents the linear regression $(r=-0 \cdot 81, P<0 \cdot 01)$.

This is not unexpected, as seed mass strongly limits initial mass, and seed mass variation within Aegilops shows a marked phylogenetic component. So, species with large seeds have high initial mass but they do not necessarily achieve a higher final mass because a high final mass is influenced more by a high RGR (Table 1).

Seed mass was not significantly correlated with other plant variables $(P>0 \cdot 10$; Table 1$)$.

Ploidy level was positively correlated with both seed mass and initial fresh mass $(P<0.001$; Table 1). The hybrids (tetraploid and hexaploid species) consistently showed larger seed and initial mass than the progenitor species (Fig. $4 a, b$ ).

Photosynthetic rate (on an area basis) did not vary significantly with ploidy level, but the photosynthetic rate on a d. wt basis was higher in progenitor species than in the hybrids $(P<0.05$; Fig. $4 c$ ), due to the slightly higher SLA and photosynthetic rate on an area basis of progenitor species.

Neither RGR nor the rest of the variables were significantly correlated with ploidy level (Table 1).

\section{Habitat effects}

As the two factors that we examined in relation to habitat (annual rainfall and altitude) were not correlated $(P>0.60)$, we considered them independently. The allocation to roots was negatively correlated with average annual rainfall in the place of origin of the seeds $(P<0 \cdot 01 ;$ Fig. 5$)$. As biomass allocation was correlated with RGR, fast-growing species showed a trend to inhabit areas of high annual rainfall (Table 1).

As in the case of the relationship between seed mass and RGR there were discrepancies in the relationship between seed mass and altitude using original trait values or contrasts. Across species, seed mass was positively correlated with altitude $(P<$ $0 \cdot 05$; Table 1 ), but there was no significant cor- relation between both variables when independent contrasts were used $(P>0 \cdot 25)$. Hybrids were characteristic of higher-altitude habitats compared with the altitude of progenitor species (Fig. $4 d$ ). However, the increase in seed mass in hybrids relative to progenitors (Fig. $4 a$ ) was not correlated $(P>0 \cdot 10)$ with the increase in altitude distribution of the hybrids (Fig. $4 d$ ).

\section{DISCUSSION}

The effect of handling the plants was qualitatively similar to that found in other studies: a decrease of RGR and SLA and an increase of plant d. wt percentage (Biddington \& Dearman, 1985; Kraus et al., 1993). However, in the present study, the effect on these parameters was minor and similar for the six species compared (Fig. 2). Therefore, the non-destructive growth analysis used in the present study is a useful tool for screening a large number of Aegilops species.

The RGR of the Aegilops species differed 1.6-fold. This range is smaller than that found in other studies with a similar number of species (e.g. 3.3 in Poorter \& Remkes, 1990; 2.5 in Marañón \& Grubb, 1993). A possible reason for the wider range in RGR in these other studies is that the species were from different genera and families. However, Garnier (1992) also found a wide range in RGR $(2 \cdot 4$-fold $)$ when comparing two species of the same genus (Bromus), but this might be because the species differed in life form (annual vs. perennial). Similarly, Atkin et al. (1996), showed large differences in RGR $(2 \cdot 3$-fold) in Poa species, but these species differed widely in altitude distribution. Taking into account that all species studied in our work, except Amplyopyrum muticum, are from the same genus (Aegilops) and have the same life form (annuals), we consider the 1.6-fold difference in RGR between these species as a fairly large range. In the following section we discuss factors that are associated with the differences in RGR for Aegilops species.

\section{RGR relationships with $N A R$ and LAR}

NAR and LAR showed a similar correlation coefficient with RGR (Table 1), in contrast with the results of other studies (see the review of Poorter \& Van der Werf, 1998); these usually show high correlations between LAR and RGR whereas NAR is usually uncorrelated with RGR.

In our study LAR is highly correlated with SLA. This suggests that variation in SLA should also play an important role in determining RGR in Aegilops spp., as found in numerous studies (see Lambers \& Poorter, 1992; Reich, Walters \& Ellsworth, 1997; Poorter \& Van der Werf, 1998). Why then did we not find any correlation of RGR with SLA (Fig. $3 a$ )? The reason appears to be the negative correlation between SLA and NAR. The higher NAR of some Aegilops 
species is partly because of their greater rate of photosynthesis per unit leaf area $\left(\mathrm{A}_{\mathrm{a}}\right)($ Table 1$)$ as has been found in other studies (e.g. Konings, 1989).

Photosynthetic rate per unit leaf area in Aegilops species was negatively correlated to SLA, which could account for the negative correlation of NAR and SLA and the absence of a correlation of SLA with RGR.

Although the rates of photosynthesis at the leaf level are not necessarily representative of photosynthesis of the whole plant, they might be considered as potential rates reflecting photosynthetic capacity. We found a wide range in photosynthetic rate at the leaf level for the 21 species studied, but this rate of photosynthesis (on an area or mass basis) was not correlated with RGR. Poorter, Remkes \& Lambers (1990) and Atkin et al. (1996) found a positive correlation between whole-plant photosynthetic rate on a mass basis and RGR. A likely reason that could explain the different results is that we found no correlation between RGR and SLA (Fig. $3 a$ ), in contrast to Poorter et al. (1990) and Atkin et al. (1996).

Other results reinforce the hypothesis that leaf photosynthetic rate is not a major factor determining variation in RGR in the Aegilops genus. First, the species with a higher photosynthetic rate were those that allocated more biomass to the roots and these species are slow growing (Table 1). Second, fastgrowing Aegilops species have large leaf blades, but photosynthetic rates were lower for species that have large leaves ('Table 1).

A negative relationship between RGR and plant d. wt percentage (Fig. $3 c$ ) was also found for 24 wild herbaceous species (Poorter \& Bergkotte, 1992) and 14 grass species (Garnier, 1992). One possible explanation for this result is that the activities of the tissues are lower when their $\mathrm{d}$. wt percentage is higher, due to the presence of proportionally more metabolically inactive components, such as cell walls and sclerenchymatic tissue (Garnier \& Laurent, 1994; Van Arendonk \& Poorter, 1994). Low RGRs are associated with both low respiration and low nutrient uptake rates (Poorter et al., 1990; Walters, Kruger \& Reich, 1993).

Our study is the first to draw attention to a positive relationship between RGR and stem mass ratio (SMR) (Fig. $3 b$ ). Stems are normally considered to be storage and support organs (White, 1973), rather than structures related to higher RGR. Even in a comparison of climbing and non-climbing herbaceous plants, in which the function of stems is expected to differ, SMR was not an important factor correlating with RGR (Den Dubbelden \& Verburg, 1996). Only Shipley and Peters $(1990 a)$ found that species with stems had a higher relative growth rate than stemless species. Interestingly, the same positive correlation between RGR and SMR is also found when 10 Triticum aestivum cultivars are included in the '20 Aegilops' data set, showing the Triticum cultivars have a higher RGR and SMR than Aegilops spp. (Van den Boogaard \& Villar, 1998).

Why is a higher investment in stem mass associated with faster growth in Aegilops spp. ? Apparently this is due to a positive correlation $(0.05<P<0 \cdot 10)$ between SMR and LAR. This correlation might indicate that plants which invest more in leaf blades (higher LAR), also need to invest more in leaf sheaths (which in our study were included in the stem fraction, and thus increasing SMR). However, positive correlations between SMR and LAR are not always found, even in other studies of grasses where leaf sheaths were included in the stem fraction (Poorter \& Remkes, 1990; Garnier, 1992; Marañón \& Grubb, 1993). Another possible reason for the higher RGR of plants with higher SMR is that species with higher SMR are taller $(P<0 \cdot 05$, data not shown), which could increase light interception and thus RGR. Finally, a large investment in stems could reflect a high concentration of gibberellins, which might affect RGR through their effect on cell division and cell expansion. Future measurements are needed to analyse the association of SMR and RGR.

\section{$R G R$, seed mass and ploidy level}

Another trait that might account for the differences in RGR in Aegilops spp. is seed mass, which differed 3.2-fold (Appendix 1). Shipley \& Peters (1990b) found that RGR is generally negatively correlated with seed mass. However, in our study the relationships between RGR and seed mass vanished when we accounted for the phylogenic relations within the genus. This indicates that the changes in seed mass and RGR in the Aegilops spp. through the evolution of the genus have not been coupled, and that the changes in both parameters were independent of each other, most likely due to an early divergence in seed mass. Within the group of species with small seeds there are species with very different RGR (Fig. 1) (e.g. Ae. uniaristata and Ae. speltoides) and the same variation exists within large-seeded species (e.g. Ae. columnaris and Ae.peregrina).

We conclude that there is no evidence for an evolutionary trend of covariation between RGR and seed mass in the Aegilops spp. Similarly, Choe et al. (1988) and Meerts \& Garnier (1996), studying closely related genotypes (from the same species), did not find a negative trend in RGR and seed mass. Meerts \& Garnier (1996) even found a positive correlation between both parameters, which was due to an unusual positive correlation between seed mass and SLA.

Ploidy level does not appear to have a large effect on RGR, allocation parameters or photosynthetic rate per unit leaf area $\left(\mathrm{A}_{\mathrm{a}}\right)$ in Aegilops spp. (Table 1). However, in contrast to our results, Evans \& Dunstone (1970) reported that diploid Aegilops and Triticum spp. do have higher photosynthetic rates on 
an area basis than tetraploids and hexaploids. The discrepancy between their and our results might be due to the use of different light intensities. Warner $\&$ Edwards (1993) concluded that the differences in photosynthetic rates with ploidy level are due to anatomical factors such as cell packing and leaf thickness, rather than to the physiology of the cells per se. Anatomical features are also likely to be important in the Aegilops spp., as progenitor species exhibit higher photosynthetic rates per unit leaf mass $\left(A_{\mathrm{m}}\right)$ than the hybrids (tetraploids and hexaploids) (Fig. $4 c$ ), due to their slightly higher SLA and $A_{\mathrm{a}}$. A higher photosynthetic rate per unit leaf mass in parental species does not cause a higher RGR, because $A_{\mathrm{m}}$ is positively correlated with root mass ratio.

It has also been suggested that small seeds have a lower DNA content per cell, which could shorten the time for cell division thus causing a higher RGR (Bennett, 1987; Marañón \& Grubb, 1993). In our study, diploid species (which presumably have a lower DNA content per cell than tetraploid and hexaploid ones) have a lower seed mass (Fig. 4a) but by contrast they do not have a higher RGR.

\section{Ecological implications}

Do any of the characteristics studied confer ecological advantages to the species in certain environments? One of these characteristics seems to be the seed mass. Plants which possess higher seed mass exhibit higher initial plant mass (Table 1), which could be essential for seedling establishment under competitive conditions (Silvertown, 1982), as a higher mass might allow a plant to compete better for nutrients, water and light.

Our results suggest that, in the Aegilops genus, to achieve a higher mass at day 20 (final mass) it is more important to have a higher RGR than a larger seed and initial seedling mass (Table 1). Van Andel \& Biere (1989) also reported that plant mass (after $12 \mathrm{wk}$ of growth) was positively correlated with RGR. The potential effect of a larger seed and a high initial mass is probably greatest for successful seedling establishment and for successful outcomes of early competitive interactions. Environmental variations during growth and development would tend to overcast the initial positive effect of large seed size (Marañón \& Grubb, 1993).

It has also been argued that larger-seeded species are from environments with a high risk of drought during seedling establishment (Salisbury, 1942; Baker, 1972). However, in Aegilops spp., seed mass was not correlated with annual rainfall (Table 1). Also, root:shoot ratios, which are usually high in drought-tolerant plants, are not higher for largerseeded Aegilops spp.

Although there is not a correlation between seed mass and altitude (Table 1) we found that the hybrids with high seed mass (Fig. 4a) are typically from higher altitude habitats than the progenitor species (Fig. $4 d$ ). One factor that could explain the higher seed mass at higher altitude habitats might be concerned with ploidy level and DNA content. Thus, smaller-seeded species are diploid (Table 1), which presumably have a lower DNA content and they also tend to be found in low-altitude habitats (Fig. $4 d$ ). This has been explained by the inhibiting effect of low temperatures (as altitude increases) on cell division in plants containing a low amount of nuclear DNA (Grime \& Mowforth, 1982; Grime, Shacklock \& Band, 1985).

Another characteristic which might have ecological importance is the pattern of biomass allocation, which is strongly associated with speciesspecific habitat characteristics. Species from areas with high annual rainfall typically show small biomass allocation to roots (Fig. 5) and large biomass allocation to stems and leaves. In habitats where water availability is high, species that allocate more biomass to the shoot are likely to be more successful. Habitats with higher annual rainfall tend to be more productive (Le Houerou \& Hoste, 1977) and in such places competition for light is more important. A greater allocation to the stem and leaves might be indispensable in such circumstances. On the other hand, plants living in low-rainfall habitats might benefit from having a larger root system, as they will compete better for water. Higher root: shoot ratios have been generally reported from drier habitats (e.g., Monk, 1966; Breymeyer, 1980).

In summary, we conclude for this first broad, within-genus comparison of RGR variation, that allocation variables are far more important in determining variation in RGR than either leaf photosynthetic rates or sLa. Fast-growing Aegilops spp. share a number of features, including higher SMR, lower RMR, larger leaves and a small percentage of plant d. wt. On the other hand, tetraploid and hexaploid species have larger seeds than diploid species. All these characteristics confer ecological advantages to species facing different environmental settings. Thus, the species with a higher proportion of roots are characteristic of drier habitats and polyploid species are adapted to higher-altitude habitats.

Our results suggest that some of the diversification within the Aegilops genus has been related to changes in the pattern of biomass allocation and ploidy level between species, which has allowed them to exploit different habitats.

\section{ACKNOWLEDGEMENTS}

We thank Michiel Van Slageren (ICARDA, International Center for Agricultural Research in the Dry Areas, Aleppo, Syria) for providing information about the Aegilops and Amblyopyrum species and John Peacock (ICARDA) for providing the seeds. We also thank Owen Atkin, Jan van Brederode, Rocío Fernández Alés, Diego García, Eric 
Garnier, Teodoro Marañón, Esther Pérez-Corona, Thijs Pons, Bill Shipley, Marion Cambridge and two anonymous referees for their valuable comments on previous versions of the manuscript. This research was supported by a Postdoctoral Fellowship (DGICYT, Dirección General de Investigación Científica y Técnica, Spain) to R.V. and by the Project PB92-0813 (DGICYT). P. J. was supported by grant PB91-0114 (DGICYT).

\section{REFERENCES}

Atkin OK, Botman B, Lambers H. 1996. The causes of inherently slow growth in alpine plants: an analysis based on the underlying carbon economies of alpine and lowland $P o a$ species. Functional Ecology 10: 698-707.

Baker HG. 1972. Seed weight in relation to environmental conditions in California. Ecology 53: 997-1010.

Bennett MD. 1987. Variation in genomic form in plants and its ecological implications. New Phytologist 106 (Supplement): $177-200$.

Biddington NL, Dearman AS. 1985. The effect of mechanically induced stress on the growth of cauliflower, lettuce and celery seedlings. Annals of Botany 55: 109-119.

Breymeyer AI. 1980. Trophic structure and relationships. In: Breymeyer AI, Dyne GM, eds. Grasslands, Systems Analysis and Man. IBP 1. Cambridge, UK: Cambridge University Press, 799-819

Choe HS, Chu C, Koch G, Gorham J, Mooney HA. 1988. Seed weight and seed resources in relation to plant growth rate. Oecologia 76: 158-159.

Cornelissen JHC, Castro Diez P, Hunt R. 1996. Seedling growth, allocation and leaf attributes in a wide range of woody plant species and types. Fournal of Ecology 84: 755-765.

Den Dubbelden KC, Verburg RW. 1996. Inherent allocation patterns and potential growth rates of herbaceous climbing plants. Plant and Soil 184: 341-347.

Donoghue MJ, Ackerly DD. 1997. Phylogenetic uncertainties and sensitivity analyses in comparative biology. In: Silvertown JW, Franco M, Harper JL, eds. Plant Life Histories : Ecology, Phylogeny and Evolution. London, UK: Cambridge University Press, $17-35$.

Dvorak J, Zhang H-B. 1990. Variation in repeated nucleotide sequences sheds light on the phylogeny of the wheat B and G genomes. Proceedings of the National Academy of Sciences, USA 87: 9640-9644.

Evans LT, Dunstone RL. 1970. Some physiological aspects of evolution in wheat. Australian fournal of Biological Science 23 $725-741$.

Feldman M. 1991. Utilization of wild gene resources from the Mediterranean in wheat improvement. Botanica Chronica 10 407-428.

Fenner M. 1983. Relationships between seed weight, ash percentage and seedling growth in twenty-four species of Compositae. New Phytologist 95: 697-706.

Fernández Alés R, Laffarga JM, Ortega F. 1993. Strategies in Mediterranean grassland annuals in relation to stress and disturbance. Fournal of Vegetation Science 4: 313-322.

García D, Rodríguez J, Panadero P, Marañón T, Villar R. 1997. Tasas de crecimiento en 21 especies de trigo silvestre y su relación con la tasa de fotosíntesis y la concentración de nitrógeno foliar. In: Sarmiento R, Leidi EO, Troncoso A, eds. Nutrición Mineral de las Plantas en la Agricultura Sostenible. Sevilla, Spain: Junta de Andalucía, Consejería de Agricultura y Pesca, 83-90.

Garland Jr T, Harvey PH, Ives AR. 1992. Procedures for the analysis of comparative data using phylogenetically independent contrasts. Systematic Biology 41: 18-32.

Garnier E. 1991. Resource capture, biomass allocation and growth in herbaceous plants. Trends in Ecology and Evolution 6 : $126-131$.

Garnier E. 1992. Growth analysis of congeneric annual and perennial grass species. Fournal of Ecology 80 : 665-675.

Garnier E, Laurent G. 1994. Leaf anatomy, specific leaf mass and water content in congeneric annual and perennial grass species. New Phytologist 128: 725-736.
Grime JP, Mowforth MA. 1982. Variation in genome size: an ecological interpretation. Nature 299: 151-153.

Grime JP, Shacklock JML, Band SR. 1985. Nuclear DNA amounts, shoot phenology and species coexistence in a limestone grassland community. New Phytologist 100: 435-445.

Gross KL. 1984. Effects of seed size and growth form on seedling establishment of six monocarpic perennial plants. Fournal of Ecology 72: 369-387.

Hunt R. 1982. Plant growth curves. The functional approach to plant growth analysis. London, UK: Edward Arnold.

Kimber G, Feldman M. 1987. Wild wheat. An introduction. Special Report 353, College of Agriculture, University of Missouri-Columbia.

Konings H. 1989. Physiological and morphological differences between plants with a high NAR or a high LAR as related to environmental conditions. In: Lambers $\mathrm{H}$, Cambridge ML, Konings H, Pons TL, eds. Causes and Consequences of Variation in Growth Rate and Productivity of Higher Plants. The Hague, The Netherlands: SPB Academic Publishing, 101-123.

Kraus E, Lambers H, Kollöffel C. 1993. The effect of handling on the yield of two populations of Lolium perenne selected for differences in mature leaf respiration rate. Physiologia Plantarum 89: 341-346.

Lambers H, Freijsen N, Poorter H, Hirose T, Van der Werf A. 1989. Analyses of growth based on net assimilation rate and nitrogen productivity. Their physiological background. In: Lambers H, Cambridge ML, Konings H, Pons TL, eds. Causes and Consequences of Variation in Growth Rate and Productivity of Higher Plants. The Hague, The Netherlands: SPB Academic Publishing, 257-267.

Lambers H, Poorter H. 1992. Inherent variation in growth rate between higher plants: a search for physiological causes and ecological consequences. Advances in Ecological Research 23 : $187-261$

Lambers H, Van den Boogaard R, Veneklaas EJ, Villar R. 1995. Effects of global environmental change on carbon partitioning in vegetative plants of Triticum aestivum and closely related Aegilops species. Global Change Biology 1: 397-406.

Le Houerou HN, Hoste CH. 1977. Rangeland production and annual rainfall relation in the Mediterranean basin and in the African Sahelo-Sudanian zone. Fournal of Range Management 30: $181-189$

Marañón T. 1987. Ecología del polimorfismo somático de semillas y la sinaptospermia en Aegilops neglecta Req. Ex. Bertol. Anales del Fardín Botánico de Madrid 44: 97-107.

Marañón T. 1988. Seed size and relative growth rate in Mediterranean annual plants. In: di Castri F, Floret $\mathrm{Ch}$, Rambal S, Roy J, eds. Time Scales and Water Stress. Paris, France: IUBS, 643-647.

Marañón T. 1989. Variations in seed size and germination in three Aegilops species. Seed Science and Technology 17 : 583-588.

Marañón T, Grubb PJ. 1993. Physiological basis and ecological significance of the seed size and relative growth rate relationship in Mediterranean annuals. Functional Ecology 7: 591-599.

Meerts P, Garnier E. 1996. Variation in relative growth rate and its components in the annual Polygonum aviculare in relation to habitat disturbance and seed size. Oecologia 108: 438-445.

Monk C. 1966. Ecological importance of root/shoot ratios. Bulletin of the Torrey Botanical Club 93: 402-406.

Poorter H, Bergkotte M. 1992. Chemical composition of 24 wild species differing in relative growth rate. Plant, Cell and Environment 15: 221-229.

Poorter H, Remkes C. 1990. Leaf area ratio and net assimilation rate of 24 wild species differing in relative growth rate. Oecologia 83: $553-559$

Poorter H, Remkes C, Lambers H. 1990. Carbon and nitrogen economy of 24 wild species differing in relative growth rate. Plant Physiology 94: 621-627.

Poorter H, Van der Werf A. 1998. Is inherent variation in RGR determined by LAR at low irradiance and by NAR at high irradiance? A review of herbaceous species. In: Lambers $\mathrm{H}$, Poorter $\mathrm{H}$, van Vuuren $\mathrm{M}$, eds. Inherent Variation in Plant Growth. Physiological Mechanisms and Ecological Consequences. Leiden, The Netherlands: Backhuys Publishers, 309-336. 
Purvis A, Rambaut A. 1995. Comparative analysis by independent contrasts (CAIC): an Apple Macintosh application for analysing comparative data. Computer Applied Biosciences 11: $247-251$.

Reich PB, Walters MB, Ellsworth DS. 1997. From tropics to tundra: global convergence in plant functioning. Proceedings of the National Academy of Sciences, USA 94: 13730-13734.

Salisbury EJ. 1942. The reproductive capacity of plants. London, UK: Bell.

Saverimuttu T, Westoby M. 1996. Components of variation in seedling potential relative growth rate: phylogenetically independent contrast. Oecologia 105: 281-285.

Shipley B. 1995. Structured interspecific determinants of specific leaf area in 34 species of herbaceous angiosperms. Functional Ecology 9: 312-319.

Shipley B, Peters RH. 1990a. A test of the Tilman model of plant strategies: relative growth rate and biomass partitioning. American Naturalist 136: 139-153.

Shipley B, Peters RH. 1990 b. The allometry of seed weight and seedling relative growth rate. Functional Ecology 4: 523-529.

Silvertown JW. 1982. Introduction to plant population ecology. London, UK: Longman.

Silvertown JW, Franco M, Harper JL. 1997. Plant life histories : ecology, phylogeny, and evolution. London, UK: Cambridge University Press.

StatSoft, Inc. 1996. Statistica for Windows 5.1 (Computer program manual). Tulsa, OK, USA.

Swanborough P, Westoby M. 1996. Seedling relative growth rate and its components in relation to seed size: phylogenetically independent contrasts. Functional Ecology 10: 176-184.

Van Andel J, Biere A. 1989. Ecological significance of variability in growth rate and plant productivity. In: Lambers $\mathrm{H}$, Cambridge ML, Konings H, Pons TL, eds. Causes and Consequences of Variation in Growth Rate and Productivity of Higher Plants. The Hague, The Netherlands: SPB Academic Publishing, 257-267.

Van Arendonk JJCM, Poorter H. 1994. The chemical composition and anatomical structure of leaves of grass species differing in relative growth rate. Plant, Cell $\mathcal{E}^{\circ}$ Environment 17 : 963-970.

Van den Boogaard R, Villar R. 1998. Variation in growth and water-use efficiency - a comparison of Aegilops species and Triticum aestivum L. cultivars. In: Lambers H, Poorter H, van Vuuren M, eds. Inherent Variation in Plant Growth. Physiological Mechanisms and Ecological Consequences. Leiden, The Netherlands: Backhuys Publishers, 289-308.

Van Slageren MW. 1994. Wild wheats : a monograph of Aegilops L. and Amblyopyrum (Faub. छ Spach) Eig (Poaceae). Wageningen, The Netherlands: Agricultural University.

Waines JG, Barnhart D. 1992. Biosystematic research in Aegilops and Triticum. Hereditas 116: 207-212.

Walters MB, Kruger EL, Reich PB. 1993. Relative growth rate in relation to physiological and morphological traits for northern hardwood tree seedlings: species, light environment and ontogenetic considerations. Oecologia 96: 219-231.

Warner DA, Edwards GE. 1993. Effects of polyploidy on photosynthesis. Photosynthetic Research 35: 135-147.

West C, Briggs GE, Kidd F. 1920. Methods and significant relations in the quantitative analysis of plant growth. New Phytologist 19: 200-207.

White LM. 1973. Carbohydrate reserves of grasses: a review. Fournal of Range Management 26: 13-18 
Appendix 1. List of the 20 Aegilops spp. studied and one Amblyopyrum sp., number of the collection code at the International Center for Agricultural Research in the Dry Areas (ICARDA, Aleppo, Syria), place of origin of the seeds, genome type and mean values $+S E(n=4)$ of different plant parameters : Seed M (air-dry seed mass); Initial M (initialf. wt at day 0); Final M (d. wt at day 20); RGR (relative growth rate); LMR (leaf mass ratio); SMR (stem mass ratio); RMR (root mass ratio); SLA (specific leaf area)

\begin{tabular}{|c|c|c|c|c|c|c|c|c|c|c|c|}
\hline Code & Species & Origin & $\begin{array}{l}\text { Genome } \\
\text { type }\end{array}$ & $\begin{array}{l}\text { Seed M } \\
(\mathrm{mg})\end{array}$ & $\begin{array}{l}\text { Initial M } \\
(\mathrm{mg})\end{array}$ & $\begin{array}{l}\text { Final M } \\
(\mathrm{mg})\end{array}$ & $\begin{array}{l}\text { RGR } \\
\left(\mathrm{mg} \mathrm{g}^{-1} \mathrm{~d}^{-1}\right)\end{array}$ & LMR & SMR & RMR & $\begin{array}{l}\text { SLA } \\
\left(\mathrm{m}^{2} \mathrm{~kg}^{-1}\right)\end{array}$ \\
\hline 401094 & Ae. caudata & Turkey & $\mathrm{C}$ & $6 \cdot 46$ & $113 \cdot 8 \pm 17 \cdot 7$ & $446 \cdot 1 \pm 25 \cdot 0$ & $163 \cdot 8 \pm 2 \cdot 4$ & $0 \cdot 43 \pm 0 \cdot 01$ & $0 \cdot 17 \pm 0 \cdot 01$ & $0 \cdot 40 \pm 0 \cdot 01$ & $18 \cdot 60 \pm 1 \cdot 47$ \\
\hline 400582 & Ae. comosa ssp. comosa & Turkey & M & $6 \cdot 57$ & $120 \cdot 0 \pm 5 \cdot 9$ & $332 \cdot 3 \pm 11 \cdot 9$ & $147 \cdot 6 \pm 4 \cdot 5$ & $0 \cdot 43 \pm 0 \cdot 01$ & $0 \cdot 15 \pm 0 \cdot 01$ & $0 \cdot 42 \pm 0 \cdot 01$ & $15 \cdot 53 \pm 1 \cdot 08$ \\
\hline 400531 & Ae. longissima & Unknown & $\mathrm{S}^{1}$ & $8 \cdot 10$ & $125 \cdot 8 \pm 12 \cdot 2$ & $307 \cdot 9 \pm 29 \cdot 1$ & $146 \cdot 8 \pm 6 \cdot 9$ & $0 \cdot 52 \pm 0 \cdot 01$ & $0 \cdot 18 \pm 0 \cdot 01$ & $0 \cdot 30 \pm 0 \cdot 01$ & $19 \cdot 81 \pm 0 \cdot 32$ \\
\hline 400902 & Ae. searsii & Syria & $\mathrm{S}^{\mathrm{s}}$ & $5 \cdot 89$ & $109 \cdot 3 \pm 4 \cdot 5$ & $313 \cdot 1 \pm 7 \cdot 8$ & $154 \cdot 5 \pm 3 \cdot 8$ & $0 \cdot 42 \pm 0 \cdot 01$ & $0 \cdot 17 \pm 0 \cdot 01$ & $0 \cdot 41 \pm 0 \cdot 01$ & $22 \cdot 96 \pm 0.53$ \\
\hline 400725 & Ae. speltoides ssp. speltoides & Syria & $\mathrm{S}$ & $6 \cdot 51$ & $103 \cdot 8 \pm 10 \cdot 7$ & $380 \cdot 4 \pm 37 \cdot 8$ & $182 \cdot 1 \pm 2 \cdot 3$ & $0 \cdot 48 \pm 0 \cdot 01$ & $0 \cdot 18 \pm 0 \cdot 01$ & $0 \cdot 34 \pm 0 \cdot 01$ & $23 \cdot 06 \pm 1 \cdot 26$ \\
\hline 400649 & Ae. tauschii & Azerbaijan & $\mathrm{D}$ & $11 \cdot 07$ & $128 \cdot 5 \pm 3 \cdot 6$ & $684 \cdot 0 \pm 26 \cdot 6$ & $187 \cdot 3 \pm 0 \cdot 5$ & $0 \cdot 44 \pm 0.01$ & $0 \cdot 21 \pm 0 \cdot 01$ & $0 \cdot 35 \pm 0 \cdot 01$ & $22 \cdot 50 \pm 0.45$ \\
\hline 400017 & Ae. umbellulata & Syria & $\mathrm{U}$ & $12 \cdot 34$ & $179 \cdot 8 \pm 16 \cdot 8$ & $511 \cdot 5 \pm 40 \cdot 5$ & $148 \cdot 2 \pm 1 \cdot 2$ & $0 \cdot 43 \pm 0 \cdot 01$ & $0 \cdot 17 \pm 0 \cdot 01$ & $0 \cdot 40 \pm 0 \cdot 01$ & $18 \cdot 76 \pm 0 \cdot 37$ \\
\hline 400547 & Ae. uniaristata & Turkey & $\mathrm{N}$ & $9 \cdot 13$ & $150 \cdot 8 \pm 3 \cdot 0$ & $435 \cdot 8 \pm 23 \cdot 1$ & $130 \cdot 7 \pm 1 \cdot 8$ & $0 \cdot 43 \pm 0 \cdot 01$ & $0 \cdot 16 \pm 0 \cdot 01$ & $0 \cdot 41 \pm 0 \cdot 01$ & $18 \cdot 91 \pm 1 \cdot 25$ \\
\hline 400274 & Am. mиticum & Turkey & $\mathrm{T}$ & $7 \cdot 50$ & $109 \cdot 3 \pm 5 \cdot 0$ & $408 \cdot 2 \pm 36 \cdot 2$ & $164 \cdot 1 \pm 4 \cdot 1$ & $0 \cdot 41 \pm 0 \cdot 02$ & $0 \cdot 20 \pm 0 \cdot 01$ & $0 \cdot 39 \pm 0 \cdot 02$ & $15 \cdot 49 \pm 1 \cdot 31$ \\
\hline 400736 & Ae. biuncialis & Syria & $\mathrm{UM}$ & $14 \cdot 21$ & $246 \cdot 5 \pm 18 \cdot 3$ & $1104 \cdot 2 \pm 66 \cdot 9$ & $159 \cdot 6 \pm 3 \cdot 2$ & $0 \cdot 50 \pm 0 \cdot 01$ & $0 \cdot 20 \pm 0 \cdot 01$ & $0 \cdot 30 \pm 0 \cdot 01$ & $15 \cdot 33 \pm 0 \cdot 41$ \\
\hline 401508 & Ae. columnaris & Syria & $\mathrm{U} \overline{\mathrm{M}}$ & $15 \cdot 04$ & $295 \cdot 8 \pm 23 \cdot 1$ & $609 \cdot 3 \pm 5 \cdot 5$ & $116 \cdot 8 \pm 11 \cdot 6$ & $0.43 \pm 0.02$ & $0 \cdot 15 \pm 0 \cdot 01$ & $0.42 \pm 0.02$ & $14.73 \pm 0.96$ \\
\hline 400715 & Ae. crassa & Syria & $\mathrm{D} \underline{\bar{M}}$ & $17 \cdot 31$ & $190 \cdot 8 \pm 9 \cdot 6$ & $401 \cdot 3 \pm 24 \cdot 4$ & $129 \cdot 6 \pm 3 \cdot 0$ & $0 \cdot 42 \pm 0 \cdot 01$ & $0 \cdot 17 \pm 0 \cdot 01$ & $0 \cdot 41 \pm 0 \cdot 01$ & $22 \cdot 72 \pm 1.06$ \\
\hline 401320 & Ae. cylindrica & Turkey & $\mathrm{DC}$ & $13 \cdot 34$ & $184 \cdot 5 \pm 17 \cdot 7$ & $701 \cdot 1 \pm 113 \cdot 9$ & $160 \cdot 5 \pm 4 \cdot 1$ & $0 \cdot 45 \pm 0 \cdot 01$ & $0 \cdot 16 \pm 0 \cdot 01$ & $0 \cdot 39 \pm 0 \cdot 01$ & $16 \cdot 73 \pm 0 \cdot 98$ \\
\hline 401007 & Ae. geniculata & Syria & $\underline{\mathrm{MU}}$ & $17 \cdot 93$ & $195 \cdot 8 \pm 4 \cdot 5$ & $541 \cdot 8 \pm 0 \cdot 1$ & $152 \cdot 8 \pm 1 \cdot 3$ & $0 \cdot 45 \pm 0 \cdot 01$ & $0 \cdot 19 \pm 0 \cdot 01$ & $0 \cdot 36 \pm 0 \cdot 01$ & $18 \cdot 13 \pm 0 \cdot 75$ \\
\hline 400885 & Ae. kotschyi & Syria & $\overline{\mathrm{SU}}$ & $12 \cdot 08$ & $192 \cdot 8 \pm 8 \cdot 9$ & $717 \cdot 3 \pm 30 \cdot 4$ & $161 \cdot 4 \pm 2 \cdot 0$ & $0 \cdot 45 \pm 0 \cdot 01$ & $0 \cdot 15 \pm 0 \cdot 01$ & $0 \cdot 40 \pm 0 \cdot 01$ & $17 \cdot 24 \pm 0 \cdot 70$ \\
\hline 401105 & Ae. neglecta & Turkey & UM & $15 \cdot 47$ & $169 \cdot 5 \pm 7 \cdot 2$ & $422 \cdot 4 \pm 35 \cdot 0$ & $135 \cdot 1 \pm 8 \cdot 1$ & $0.48 \pm 0.02$ & $0 \cdot 15 \pm 0 \cdot 01$ & $0 \cdot 37 \pm 0 \cdot 01$ & $16 \cdot 59 \pm 1.47$ \\
\hline 401290 & Ae. peregrina & Syria & $\mathrm{SU}$ & $15 \cdot 88$ & $227 \cdot 5 \pm 16 \cdot 8$ & $1005 \cdot 3 \pm 50 \cdot 8$ & $169 \cdot 8 \pm 1 \cdot 8$ & $0 \cdot 47 \pm 0 \cdot 01$ & $0 \cdot 21 \pm 0 \cdot 01$ & $0 \cdot 32 \pm 0 \cdot 01$ & $19 \cdot 99 \pm 0 \cdot 66$ \\
\hline 401501 & Ae. triuncialis & Syria & $\mathrm{UC}, \mathrm{CU}$ & $9 \cdot 09$ & $168 \cdot 5 \pm 16 \cdot 5$ & $743 \cdot 4 \pm 34 \cdot 5$ & $171 \cdot 3 \pm 3 \cdot 4$ & $0 \cdot 47 \pm 0 \cdot 01$ & $0 \cdot 18 \pm 0 \cdot 01$ & $0 \cdot 35 \pm 0 \cdot 01$ & $17 \cdot 48 \pm 0 \cdot 65$ \\
\hline 401446 & Ae. ventricosa & Algeria & $\mathrm{DN}$ & $18 \cdot 60$ & $180 \cdot 3 \pm 19 \cdot 8$ & $927 \cdot 1 \pm 56 \cdot 1$ & $173 \cdot 2 \pm 8 \cdot 7$ & $0.47 \pm 0.03$ & $0 \cdot 19 \pm 0 \cdot 01$ & $0 \cdot 34 \pm 0 \cdot 02$ & $21 \cdot 34 \pm 0 \cdot 49$ \\
\hline 401483 & Ae. juvenalis & Uzbekistan & DMU & $18 \cdot 76$ & $281 \cdot 8 \pm 11 \cdot 2$ & $505 \cdot 4 \pm 36 \cdot 4$ & $128 \cdot 3 \pm 4 \cdot 2$ & $0 \cdot 44 \pm 0 \cdot 01$ & $0 \cdot 16 \pm 0 \cdot 01$ & $0 \cdot 40 \pm 0 \cdot 01$ & $19 \cdot 86 \pm 0 \cdot 47$ \\
\hline 401842 & Ae. vavilovii & Syria & DMS & $15 \cdot 87$ & $192 \cdot 0 \pm 12 \cdot 3$ & $667 \cdot 6 \pm 46 \cdot 5$ & $152 \cdot 8 \pm 3 \cdot 5$ & $0 \cdot 44 \pm 0 \cdot 01$ & $0 \cdot 18 \pm 0 \cdot 01$ & $0 \cdot 38 \pm 0 \cdot 01$ & $19 \cdot 81 \pm 0 \cdot 47$ \\
\hline
\end{tabular}

Mean Seed M was calculated from two batches of 10 seeds each. Nomenclature is according to Van Slageren (1994) and genome type according to Waines
Tetraploids and hexaploids are cited as 'female $\times$ male parent'. Underlining indicates modification from the same genome type present in the diploid species. 